\title{
Terminologias matemáticas em Libras: a geometria plana e espacial
}

\author{
Mathematical terminologies in libras: the plane and spatial \\ geometry
}

Terminologías matemáticas en puntos: geometría plana y espacial

\begin{abstract}
Luciana Carlize Juliani Smolski - Universidade Regional Integrada do Alto Uruguai e das Missões, Santo Ângelo, Brasil (e-mail:lucianasmolski12@ gmail.com),
\end{abstract}

Rozelaine de Fatima Franzin-Universidade Regional Integrada do Alto Uruguai e das Missões, Santo Ângelo, Brasil (e-mail: rozelaine@ san.uri.br),

Antonio Vanderlei dos Santos -Universidade Regional Integrada do Alto Uruguai e das Missões, Santo Ângelo, Brasil (e-mail: vandao@san.uri.br),

Marcelo Paulo Stracke - Universidade Regional Integrada do Alto Uruguai e das Missões, Santo Ângelo, Brasil (e-mail: stracke@san.uri.br)

Resumo: Este estudo trata da interpretação para Libras-Língua Brasileira de Sinais de terminologias matemáticas usadas na geometria plana e espacial como instrumento facilitador ao intérprete de sinais e ao professor de matemática, que trabalham com alunos surdos. A metodologia caracteriza-se como exploratória e os dados foram coletados por meio de levantamento bibliográfico e pesquisa de campo. Após a coleta de dados, a partir da entrevista estruturada, como instrumento, o discurso dos participantes e, também, das respostas dos sujeitos envolvidos, as mesmas foram organizadas e analisadas, de tal modo que os questionamentos revelaram papel determinante para nortear a construção da web site denominada "Geometria Plana e Espacial em Libras". Teve como objetivo identificar os sinais que estão sendo utilizados para a educação de surdos, com o conteúdo proposto nas escolas que foram objeto da pesquisa. A análise indicou que, por mais empenho que se tenha uma inclusão na escola regular de surdos ainda existe uma carência em convencionar sinais de termos utilizados na disciplina de matemática.

Palavras-chave: Geometria Plana e Espacial; Libras; Educação de surdos.

Abstract: This study deals with the translation into Libras of mathematical terminologies used in flat and spatial geometry as a facilitating tool for the sign interpreter and the mathematics teacher, who work with deaf students. The methodology is characterized as exploratory and the data were collected through bibliographic survey and field research. After data collection, from the structured interview, as an instrument, the speech of the participants and, also, of the responses of the subjects involved, they were organized and analyzed, in such a way that the

Recebido em: 10/07/2020

Aceito em: $1 \% 12 / 2020$ 
questions revealed a determining role in guiding the construction of the web site called "Flat and Spatial Geometry in Libras". It aimed to identify the signs that are being used for the education of the deaf, with the content proposed in the schools that were the object of the research. The analysis indicated that, despite the efforts made to include students with deafness in the regular school, there is still a lack of agreeing on signs of terms used in the discipline of mathematics.

Keywords: Plane and Spatial Geometry; Libras; deaf education.

Resumen: Este estudio trata de la traducción a Libras de terminologías matemáticas utilizadas en geometría plana y espacial como una herramienta facilitadora para el intérprete de signos y el profesor de matemáticas, que trabajan con estudiantes sordos. La metodología se caracteriza por ser exploratoria y los datos se recolectaron mediante encuestas bibliográficas e investigaciones de campo. Después de la recopilación de datos, a partir de la entrevista estructurada, como instrumento, el discurso de los participantes y, también, de las respuestas de los sujetos involucrados, se organizaron y analizaron de tal manera que las preguntas revelaron un papel determinante en la orientación de la construcción de sitio web llamado "Geometría plana y espacial en Libras". Su objetivo era identificar los signos que se utilizan para la educación de los sordos, con el contenido propuesto en las escuelas que fueron objeto de la investigación. El análisis indicó que, a pesar de los esfuerzos realizados para incluir a los estudiantes con sordera en la escuela regular, todavía hay una falta de acuerdo sobre los signos de los términos utilizados en la disciplina de las matemáticas.

Palabras clave: Geometría plana y espacial; Libras; Educación para sordos.

\section{INTRODUÇÃO}

Dissertar sobre a educação matemática para alunos surdos exige evidenciar que o surdo durante muito tempo, viveu a margem da sociedade, apresentando muitas dificuldades para se comunicar e interagir, sendo tratado de forma como se não fosse possível educa-lo e como se a sua limitação auditiva determinasse essa condição da dificuldade da aprendizagem. Infelizmente esse ponto de vista se ampliou para dentro da escola onde muitos professores não tem conhecimento da Língua Brasileira de Sinais, em detrimento a aprendizagem dos alunos surdos

No Brasil, em 1856, deu-se início a educação de surdos em escolas especiais. Já na década de 70, reformas aconteceram na educação, buscando a inclusão, assim os surdos tiveram a oportunidade de estudar na escola regular e seu direito de ter um tradutor/interprete foi sendo pleiteado e com o passar dos anos. Em meados do século XX acorreu diminuição de exclusão de alunos surdos das escolas regulares, segundo Zuffi, Jacomelli, Palombo (2011, p. 2): “ocorreu certa redução da segregação e da 
exclusão, através do desenvolvimento de escolas e/ou classes especiais em escolas públicas, instituições especiais capazes de lhes proporcionar uma educação que respeitasse suas limitações.”

Na década de 80, deu-se início ao pensamento para a utilização da Libras e verificou-se sua importância na comunicação, duas décadas depois, no ano de 2000, acorreu o lançamento do dicionário Libras/Português. Em 2002 é sancionada Lei $n^{\circ}$ 10.436 que reconhece a Libras como meio de comunicação para com os surdos.

Mas infelizmente, a surdez ainda é considerada uma limitação que, define o fracasso escolar, mesmo quando o intérprete acompanha o aluno, nasce aí à importância do professor de matemática, bem como de outras disciplinas, saber se comunicar por meio da Libras, visto que no Brasil, como em outros países, foi adotado o modelo bilíngue de educação de surdos.

A educação matemática para alunos surdos está vinculada ao processo de comunicação que se estabelece com o educador. Em busca realizada no mês de abril de 2020 no https://www.eric.ed.gov/, utilizando a palavra de busca "teaching+the+deaf" não se encontrou publicação de resultados de pesquisa nos anos de 2019 e 2020. Isso mostra a carência e a importância da realização desse estudo. Escolheu-se o site de busca devido a ERIC - Centro de Informações sobre Recursos Educacionais, com base em dados de referência do Instituto de Ciências da Educação (IES) do Departamento de Educação dos EUA, que contém mais de 1,6 milhões de referências bibliográficas e resumos de artigos científicos nas áreas de Ciências da Educação.

A educação bilíngue, para alunos surdos é muito importante, afim de que possam ter uma compreensão mais eficaz de conceitos e também sua interação dentro da sociedade que está inserido. Segundo Slomski (2012), a Libras é fundamental no processo comunicativo na escola e comunidade. Assim, percebe-se a importância de uma interpretação mais precisa possível, do português para a Libras, de forma que, nesse processo, informações importantes não se percam. Para isso, verifica-se a disponibilidade de dicionários ilustrados de Libras.

Em conteúdos matemáticos, essa tradução (Matemática para a Libras) tem papel principal na aprendizagem, levando em consideração a complexidade de sua linguagem, que pode apresentar empecilhos para o aprendizado. Além disso, segundo Arnoldo Junior e Geller (2012, p. 3) "a ausência de sinais e criação de sinais específicos em 
matemática é uma emergência em muitas pesquisas contemporâneas". Contudo, ainda pode-se perceber a necessidade de estudos e pesquisas que contribuam com a discussão da tradução de terminologias específicas para as mais diversas áreas do conhecimento, tendo em vista a apropriação de conteúdo do processo de ensino aprendizagem (CAI et al, 2019).

Devido à quantidade de conteúdos matemáticos, tanto na educação básica, quanto no ensino superior, o objeto de pesquisa escolhido foram os sinais para a educação de geometria plana e espacial. A escolha por este conteúdo matemático efetivou-se pela grande dificuldade de aprendizado, tanto por alunos ouvintes, como por alunos surdos, em razão de apresentar nomenclaturas específicas.

Levando em consideração os direitos assegurados pelos surdos, pela Lei no 10.436, de 24 de abril de 2002, para a utilização da Libras na comunicação, sua inclusão na escola regular, e respeitando suas particularidades para a aprendizagem (QUADROS, 2012). A problemática da pesquisa visa buscar como ferramenta de auxílio, terminologias matemáticas que contribuam para a comunicação professor de matemática-aluno e consequentemente uma aprendizagem mais significativa por parte do aluno surdo. Sendo assim, levanta-se a seguinte questão de pesquisa: os sinais disponíveis em dicionários ilustrados de Libras e que a comunidade de estudantes surdos, professores e intérpretes utilizam, são suficientes para a tradução de terminologias matemáticas em geometria plana e espacial, visando a aprendizagem destes conteúdos matemáticos por alunos surdos?

A coleta dos dados foi realizada em três escolas eleitas para a pesquisa, estas de educação especial para alunos surdos, devido ao maior conhecimento sobre o assunto, junto aos professores de matemática que ali lecionam. Pensou-se que buscar dados em escolas especiais para alunos surdos, devido a dificuldade de encontrar professores que estariam trabalhando no momento da realização da pesquisa, com alunos surdos na escola regular inclusiva.

Eles foram contatados e convidados para a realização da aplicação de um questionário, com a devida autorização da direção da escola, de forma pessoal pelo pesquisador. Em seguida, analisados os referenciais bibliográficos e as entrevistas dos sujeitos envolvidos no processo da pesquisa, se constituiu, então, uma web site de terminologias matemáticas em Libras.

Recebido em: $10 / 07 / 2020$

Aceito em: $1 \% 12 / 2020$ 
O objetivo geral da pesquisa foi identificar quais são os sinais em Libras e classificadores (sinais convencionados entre educadores e alunos surdos) utilizados pelos professores das escolas, Escola de Ensino Médio Concórdia para Surdos de Santa Rosa - RS, Escola Estadual Especial de Ensino Médio Helen Keller, Caxias do Sul - RS e Escola Estadual Reinaldo Fernando Cóser, Santa Maria - RS, para o ensino de geometria plana e espacial. Além de avaliar se estes sinais em Libras utilizados pelos professores podem contribuir de forma efetiva, para ensino de matemática nas escolas especiais para alunos surdos, e assim posteriormente se utilizado nas escolas de educação básica inclusivas.

\section{Referencial teórico}

\subsection{Sujeito surdo}

A constituição de um sujeito inicia-se desde seu nascimento e os caminhos, decisões e opções dependem das experiências e estímulos vividos por ele. Mesmo assim, ao longo do processo de desenvolvimento, é possível viver novos conhecimentos que redefinam antigas escolhas. Neste sentido, encontra-se base na afirmação de VeigaNeto apud REZENDE (2010, p. 28) “cada um de nós é único enquanto sujeito constituído por experiências e por saberes de diferentes campos de saber". Os cientistas são moldados por suas experiências de vida únicas e trazem essas perspectivas para suas pesquisas. A diversidade de experiências culturais e de vida entre os cientistas, portanto, amplia as direções da pesquisa e, finalmente, as descobertas científicas.

A Constituição Federal do Brasil, em seu Artigo $5^{\circ}$ institui que:

Todos são iguais perante a lei, sem distinção de qualquer natureza, garantindose aos brasileiros e aos estrangeiros residentes no País a inviolabilidade do direito à vida, à liberdade, à igualdade, à segurança e à propriedade. (BRASIL, 1988)

Reafirmando essa ideia da igualdade de todos e todas perante a lei, o Estatuto da Pessoa com Deficiência, instituído pela Lei no 13.146, de 6 de julho de 2015, em seu Capítulo II, “Da igualdade e da não discriminação", determina que:

Art. $4^{\circ}$ Toda pessoa com deficiência tem direito à igualdade de oportunidades com as demais pessoas e não sofrerá nenhuma espécie de discriminação. $\S 1^{\circ}$ Considera-se discriminação em razão da deficiência toda forma de distinção, restrição ou exclusão, por ação ou omissão, que tenha o propósito ou o efeito de prejudicar, impedir ou anular o reconhecimento ou o exercício dos direitos e das liberdades fundamentais de pessoa com deficiência, incluindo a recusa de adaptações razoáveis e de fornecimento de tecnologias assistivas. 
No sujeito Surdo, a especificidade que o diferencia é sua forma modal, ou seja, a maneira de estar no mundo. A maior parte das pessoas vivenciam e percebem o mundo pela modalidade oral-auditiva (canal auditivo), enquanto os Surdos utilizam a modalidade visual-espacial (canal visual).

(...) os surdos compuseram uma forma de leitura do mundo, parte de uma cultura visual que possibilita construir conhecimento e compreender o ambiente ao seu redor. Diferentemente, o ouvinte é um sujeito verbal/oral - a audição e a fala são seus meios principais de entender o mundo, muito antes da existência da escrita. (PERLIN e SOUZA, 2015, p. 6)

Por este motivo, o surdo e seu universo tornam-se uma questão complexa, pois envolve discussões muito específicas que alguns, por vezes, entendem como segregadora e outros, como necessidade de valorização e reconhecimento da diferença.

Conforme afirma Skliar (2013, p. 11) as diversas representações sobre o sujeito Surdo reafirmam que" (...) a surdez constitui uma diferença a ser politicamente reconhecida; a surdez é uma experiência visual; a surdez é uma identidade múltipla ou multifacetada e, finalmente, a surdez está localizada dentro do discurso sobre a deficiência"

A ideia da diversidade aparece no sentido de abarcar as diversas características do sujeito Surdo, inserido num contexto social e educacional. Neste sentido,

A 'diversidade' cria um falso consenso, uma ideia de que a normalidade hospeda os diversos, porém mascara normas etnocêntricas e serve para conter a diferença. Entendo 'diferença', conforme McLaren (1995), não como um espaço retórico - a surdez é uma diferença - mas como uma construção histórica e social, efeito de conflitos sociais, ancoradas em práticas de significação e de representações compartilhadas entre os surdos. (SKLIAR, 1998, p. 13)

\subsection{Aluno surdo e ensino}

As pessoas ouvintes crescem e se desenvolvem em um mundo dominado pela linguagem oral, consequentemente estão sempre cercadas por informações que são captadas por nossos ouvidos. Da associação dos sons com as nossas experiências surge a aprendizagem. No caso do surdo, em muitos casos não existe a fala, de tal modo terá que ser utilizada outra forma para a comunicação, a Libras, língua de fácil aprendizagem, promoveria sua interação com o mundo.

Segundo Borges e Nogueira (2014, p. 127) “antes do ingresso no Ensino Fundamental, ainda criança, nossos futuros estudantes reúnem uma gama de informações advindas de diversas fontes: família, desconhecidos, amigos, brincadeiras, etc. [...]”. Para Viande e 
Fuentes (2013, p.381), a “[...] escassez de experiências educacionais prévias à escolarização (aquilo que se costuma chamar de conhecimento incidental) [...]" acaba dificultando o acesso do estudante [surdo] ao currículo da escola. O surdo ou deficiente auditivo desconhece essas informações prévias, e, portanto, eles apresentam necessidades especiais para a aprendizagem, onde define Schneider:

[...] modalidade da educação escolar, deve-se entender um processo educacional definido, uma proposta pedagógica que assegure recursos e serviços educacionais especiais, organizados institucionalmente para apoiar, complementar, suplementar e, em alguns casos substituir os serviços educacionais comuns, de modo a garantir a educação escolar e promover o desenvolvimento de potencialidades dos educandos que apresentam necessidades educacionais especiais [...] (2006, p. 89).

As escolas de educação básica estão recebendo alunos surdos, e o professor disciplina de matemática faz parte deste processo de inclusão. Sendo assim, educadores que atuam em sala de aula ou que ainda estão cursando licenciatura em matemática, cada vez mais, devem buscar aperfeiçoamento para comunicação em Libras.

Para Franzin e Geller, “os professores na sua maioria precisam de capacitação para obtenção de conhecimento necessário para organizar suas aulas dentro desse contexto, adotando metodologias e estratégias adequadas para alunos surdos.”(2019, p.365).

Conceitos, legislações e autores são discutidos para pautar a interpretação sobre a realidade histórico, social e política do ser Surdo, da Cultura Surda e sobre a Língua Brasileira de Sinais (Libras). A Língua Brasileira de Sinais é o meio de comunicação dos indivíduos surdos, a crença mais comum é que ela é universal. Conforme Gesser (2009), isso não se confirma, cada região ou país possui suas particularidades nos sinais, ainda segundo Gesser (2009, p. 11) “[...] sabemos que nas comunidades orais, [de] cada país, por exemplo, tem sua (s) própria (s) língua (s). "No caso da matemática esse fato também é constatado e, quando não há um sinal específico para determinada terminologia matemática, esse é criado e combinado para ser utilizado apenas na turma em que os alunos surdos estão inseridos para aquele determinado momento da aprendizagem.

Para o indivíduo surdo, a primeira língua é a de sinais, dessa forma, a partir dela, adquire-se subsídios para a aprendizagem da segunda língua (português), que é escrita e também pode ser entendida de forma visual. (PEREIRA et al, 2011). A língua de sinais é visual e espacial, ou seja, "necessita do espaço e da visão para a visualização comunicativa" (COSTA; SILVEIRA, 2014, p. 4). 
É direito do aluno surdo a comunicação por meio da Libras e que o sistema educacional deve ofertar cursos de capacitação em níveis médio e superior. Levando em consideração o fato de que, o professor ouvinte convive com alunos surdos basicamente em ambiente escolar.

Além disso, é preciso adequar os currículos escolares, considerando essa diferença de aprendizagem ainda no ingresso à escola, pois, se há uma dificuldade e esta persiste para a maioria dos surdos, essa adaptação é necessária se os objetivos forem um ensino e um aprendizado de boa qualidade. (FRANZIN, GELLER, 2019, p.364).

No aspecto da aprendizagem, a literatura infere que as maiores dificuldades dos surdos, principalmente dos filhos de pais ouvintes, o que é mais frequente, dizem respeito às atividades que envolvem a compreensão e uso da linguagem oral e/ou escrita Fernandes apud Silva; Pereira (2011).

Portanto, o fato de o estudante surdo ser bilíngue não é suficiente para uma aprendizagem efetiva. Torna-se necessária metodologias diferenciadas, voltadas para as especificidades da pessoa surda, para que estes indivíduos sejam inseridos no ambiente escolar. Neves (2011b, p. 2) defende que "a matemática para o surdo deve ser ensinada a partir da possibilidade de contextualização dos fatos numéricos onde é possível a negociação dos significados matemáticos favorecendo assim a construção de conceitos." A identidade surda dos indivíduos deve ser levada em consideração na construção de aprendizagens, para fins de se tornar significativas.

Deve-se ressaltar aqui que essa é uma preocupação também de pesquisadores de outros países como na Universidade do Novo México, que estão investigando a interseção entre os Padrões Comuns no campo da Educação para Surdos, especificamente o impacto do Núcleo Comum na prática pedagógica de professores de matemática para surdos e com deficiência auditiva. Define-se pedagogia neste estudo como a união da filosofia de ensinar, de um professor e a metodologia de ensino que ele usa em sala de aula (HARRISON, 2018).

Quando o aluno surdo se insere no mundo da comunicação por meio da Libras, vê-se a necessidade de professores e comunidade escolar se apropriar desse conhecimento, visando a comunicação e, consequentemente, uma aprendizagem com significados efetivos por parte do público surdo. 


\section{Metodologia e caracterização da pesquisa}

Para a realização do estudo, em um primeiro momento, foi efetuada uma revisão bibliográfica, apresentando as especificidades da aprendizagem dos alunos surdos e, de forma breve, abordada a questão da inclusão nas escolas de educação básica regular.

Para a realização das discussões, acerca das terminologias matemáticas, foi realizada uma pesquisa junto às Escolas; Escola de Ensino Médio Concórdia para Surdos, no município de Santa Rosa - RS, na Escola Estadual de Educação Especial Dr. Reinaldo Fernando Cóser, no Município de Santa Maria - RS, e na Escola Estadual de Educação Básica Ellen Keller, no município de Caxias do Sul-RS.

Participaram da pesquisa 3 (três) professores da escola de Caxias do Sul-RS, 2 (dois) deles do ensino médio e 1 (um) do ensino fundamental. Das escolas de Santa Maria - RS e Santa Rosa - RS participaram apenas 1 (um) em cada instituição. Saliento que, a escolha dos professores de matemática participantes da pesquisa ficou a cargo de cada diretor ou coordenador pedagógico das escolas envolvidas.

As entrevistas foram realizadas presencialmente, inclusive, para gestores das escolas que desejassem observar e, em alguns casos, interagir. O questionário foi composto de 9 (nove) questões, com respostas abertas, ou seja, o professor poderia colocar o que julgasse necessário para contribuir com a pesquisa. $\mathrm{O}$ questionário/entrevista, foi confeccionada e aplicada visando melhor colocação das perguntas para, de forma posterior, ser realizada uma minuciosa análise das opiniões expressas. A coleta dos dados ocorreu em um período de dois meses.

O trabalho caracterizou-se por um estudo de campo que "permite a aproximação do pesquisador da realidade sobre a qual formulou uma pergunta, mas também estabelecer uma interação com os “atores”[da pesquisa]” (MINAYO, 2012, p. 61).

Após a coleta de dados, a partir da entrevista/questionário estruturada, como instrumento, o discurso dos participantes e, também, das respostas dos sujeitos envolvidos, as mesmas foram organizadas e analisadas, de tal modo que os questionamentos revelaram papel determinante de nortear a entrevista. Uma conversa adicional com os participantes da entrevista, ou seja, as apresentações e falas realizadas fora do questionário, também foi considerada na análise dos dados coletados.

Abaixo se encontram as questões norteadoras das entrevistas:

Recebido em: $10 / 07 / 2020$

Aceito em: $1 \% 12 / 2020$ 
Questão 1- Há quanto tempo trabalha com alunos surdos?

Questão 2- O que o levou a trabalhar com alunos surdos?

Questão 3- Que tipo de material utiliza para trabalhar geometria espacial e geometria plana com estes alunos surdos?

Questão 4- O material que vem utilizando é suficiente para dar conta dos conteúdos de geometria plana e espacial?

Questão 5- Que metodologia utiliza, atualmente, para trabalhar geometria plana e geometria espacial?

Questão 6- Os sinais matemáticos conhecidos pela comunidade surda são suficientes para trabalhar geometria plana e espacial?

Questão 7- Para um melhor entendimento do conteúdo de geometria plana e geometria espacial trabalhado, você costuma "criar" um sinal, se necessário?

Questão 8- Levando em consideração os conteúdos de geometria plana e espacial, existem limitações nos sinais conhecidos para trabalhar em sala de aula?

Questão 9- Concorda em disponibilizar esse material de geometria plana e geometria espacial para posterior análise pelo pesquisador (a)?

\section{Questionário confeccionado pela autora da pesquisa.}

As análises dos referenciais bibliográficos selecionados, análise das entrevistas que foram realizadas em períodos de tempo diferentes e conversação dos sujeitos envolvidos no processo, bem como vídeos enviados pelas participantes da entrevista, levou a construção de uma web site pela autora da pesquisa, de terminologias matemáticas em geometria plana e espacial em Libras que poderão ser utilizadas na comunicação entre professores de matemática, ILS e alunos surdos.

Abaixo se encontram as questões norteadora da avaliação feita pelos professores pesquisadores das escolas:

1 - O web site na sua opinião é de fácil manuseio? Justifique de forma sucinta a sua resposta.

2 - O web site pode ser utilizado nas suas aulas, quando ministrado o conteúdo de geometria plana e espacial, como um auxiliar na aprendizagem? Justifique de forma sucinta a sua resposta. 
3 - Quer fornecer alguma sugestão para o melhoramento da web site, com intuito de utilização em sala de aula?

4 - Espaço aberto para qualquer comentário referente a pesquisa e a web site produzido e a pesquisa da qual participou.

Vale salientar que a entrevista/questionário foi escolhida como forma de coleta de dados, devido a maior facilidade de registro das informações, e posterior analise para a construção da web site.

Questionário confeccionado pela autora da pesquisa.

\section{Resultados e análise dos dados coletados}

Verificou-se, por meio dos dados da pesquisa, que os professores das escolas têm visões diferentes em alguns pontos da entrevista, o que diferencia de outros trabalhos já realizados. Nos Estados Unidos da América, um estudo de caso fenomenológico de um programa abrangente de preparação para professores de educação para surdos, de nível de pós-graduação, em uma universidade do centro-oeste explorou a capacitação de candidatos a professores usando os pilares de educador do Departamento de Ensino Fundamental e Médio do Missouri: (a) compromisso com a profissão, (b) proficiência na prática e (c) impacto na aprendizagem, todos considerados críticos para o desenvolvimento de professores de qualidade.

Foi encontrada uma forte conexão entre a filosofia abrangente do programa e sua prática. Os candidatos a professor demonstraram um excelente compromisso com a profissão e alta proficiência na prática. Os resultados sugerem que uma consideração adicional deve ser dada à sala de aula e ao gerenciamento do comportamento, carga de trabalho dos professores candidatos, ensino além dos acadêmicos e preparação para a navegação no sistema escolar público. (ENGLER, MACGREGOR, 2018).

$\mathrm{Na}$ pesquisa foi identificado que a maioria dos docentes tem anos consideráveis de trabalho em escola de educação para surdos. Dos professores participantes da pesquisa, 4 (quatro) são ouvintes e 1 (uma) é surda oralizada. Todos os entrevistados acentuam que utilizam muito a questão do visual, do concreto, que partem de situações onde o aspecto da visão é canal principal da aprendizagem, levando em consideração a falta de audição dos educandos. 
É citado por um professor da escola especial para alunos surdos entrevistados, o fato de que o material didático utilizado, na maioria dos casos, é elaborado para alunos ouvintes, razão pela qual deve ser adaptado para alunos surdos, ou seja, não há disponibilidade de material específico para esse público. Os professores relataram a importância das tecnologias como aliado na aprendizagem de alunos surdos, devido ao apelo visual que oferecem.

Além de toda a tecnologia disponível, os educadores trabalham com os sólidos geométricos, construídos de material acrílico, vidro, madeira ou até mesmo papel. São produzidos, também, em conjunto com os alunos, grandes cartazes, os quais são dispostos em forma de fácil visualização por todos na escola.

Quando a entrevista foi conduzida para a questão da disponibilidade de sinais na área de matemática, principalmente para o alvo da pesquisa, que é a disponibilidade de sinais em geometria plana e espacial, os professores expõem que fazem o uso dos classificadores e que, se necessário, são "criados" sinais em conjunto com seus alunos, naquele momento e naquela aula para o público específico de alunos. Não havendo nenhum tipo de registro, seja na forma de vídeo ou fotografia, do sinal sendo efetuado.

A grande maioria reconhece que faltam sinais para o conteúdo do estudo, fato esse que pode ser justificado pela pouca interação entre as escolas. As discussões e alternativas efetivam-se por meio de seminários e encontros realizados anualmente, nos quais um sinal não pode simplesmente ser criado por conta de um professor, ele deve ser discutido e aceito dentro da comunidade surda.

Assim, o professor fica condicionado ao uso do classificador, pois ainda se encontra limitações na comunicação entre as comunidades surdas e escolas de surdos do Estado do Rio Grande do Sul, para que os sinais matemáticos que estão sendo utilizados em determinada região, sejam de conhecimento de outra. Quando questionado os professores sobre a disponibilização do seu material de Libras-matemática, para análise e colaboração com a pesquisa, todos, com exceção de 1 (um), afirmaram que estaria à disposição do pesquisador.

De imediato foram enviados materiais como apostilas e dicionários de Librasmatemática. Em 2 (duas) escolas os professores pediram um determinado tempo para a produção de vídeos ou fotos dos sinais utilizados em geometria plana e espacial, sendo 
que, apenas em 1 (uma) escola pesquisada, não houve nenhum envio de material. Sendo assim, constatou-se que o registro, exposição ou publicação do que está sendo produzido nas escolas de educação básica especial (não posso afirmar sobre a escola básica regular, a pesquisa não foi feita nela) para surdos ainda não é suficiente ou mesmo não acontece. Muitos educadores não encontram meio para fazê-lo, dado a falta de conhecimento do assunto ou a ausência de tempo disponível para o trabalho científico, realizado em universidades, por exemplo.

Com os dados coletados, por meio do questionário/entrevista e conversas realizadas, destaca-se a "importância que estabeleçamos confrontos entre: dimensão subjetiva e posicionamentos de grupos; texto e subtexto; texto e contexto; falas e ações mais amplas; cognição e sentimento [...]" (GOMES, 2012, p. 105), ainda se tem um caminho longo a percorrer no que diz respeito a uma maior uniformidade de sinais matemáticos de geometria plana e espacial, bem como a concepção de sinais que ainda não existem.

Almeja-se que este aluno surdo seja capaz de concluir o ensino médio, tornar-se um cidadão atuante na sua comunidade e capaz de ingressar em um curso técnico ou curso superior, alcançando, dessa forma, sua profissionalização.

\subsection{Guia e usabilidade de terminologias matemáticas: geometria plana e espacial em Libras}

O processo de construção do guia das terminologias matemáticas para a geometria plana e espacial em Libras é abordado a seguir. O material foi confeccionado com base nas pesquisas, por meio da entrevista/questionário, realizadas nas escolas de educação especial para surdos, supra citadas.

No decorrer das pesquisas, optou-se pela construção de uma web site, que está disponível em DVD, construída com a linguagem de programação HTML - Hyper Text Markup Language (Linguagem de marcação de texto), que se mostrou de simples manuseio, suprindo as necessidades da web site proposta. Verificou-se, durante o processo de pesquisa, que as tecnologias, na educação de surdos, têm um papel fundamental como aliado na aprendizagem, bem como a utilização da internet.

O indivíduo surdo necessita de um amplo apelo visual no momento da aprendizagem. Dessa forma, utilizando a internet tem-se disponível, por exemplo, “[...] 
animação de imagens, sinais gráficos, que são de muito fácil compreensão para o surdo [...]" (ROSA; CRUZ, 2001, p. 43). Na internet, pode-se encontrar sites que são especialmente voltados para interação com o estudante surdo, expondo uma preocupação especial com a tradução para a Libras dos termos em português.

Segundo Batista e Motta (2006), para a criação da web site são necessários conhecimentos prévios de arquivos html e de sua forma de programação.

Um arquivo $H T M L$ é um arquivo de texto contendo pequenas marcações que serão interpretadas por um browser (como o Mozilla Firefox por exemplo). Estas marcações são chamadas de TAGs (ou etiquetas). As tags mostram ao browser como exibir a página. Um arquivo $H T M L$ deve ter a extensão $h t m$ ou $h t m l$ e pode ser criado usando um editor de texto comum (2006, p. 15).

A web site desenvolvida, denominado Geometria Plana e Espacial em Libras, tem como objetivo mostrar os sinais que estão sendo utilizados para a educação de surdos, com om conteúdo proposto nas escolas que foram objeto da pesquisa. Utiliza um formato interativo, com várias cores e de agradável manuseio tanto para surdos quanto para ouvintes que busquem esse conhecimento, bem como traz vídeos e ilustrações dos sinais. Na figura apresenta-se a página da Web site:

Figura- Vista da página da Web Site
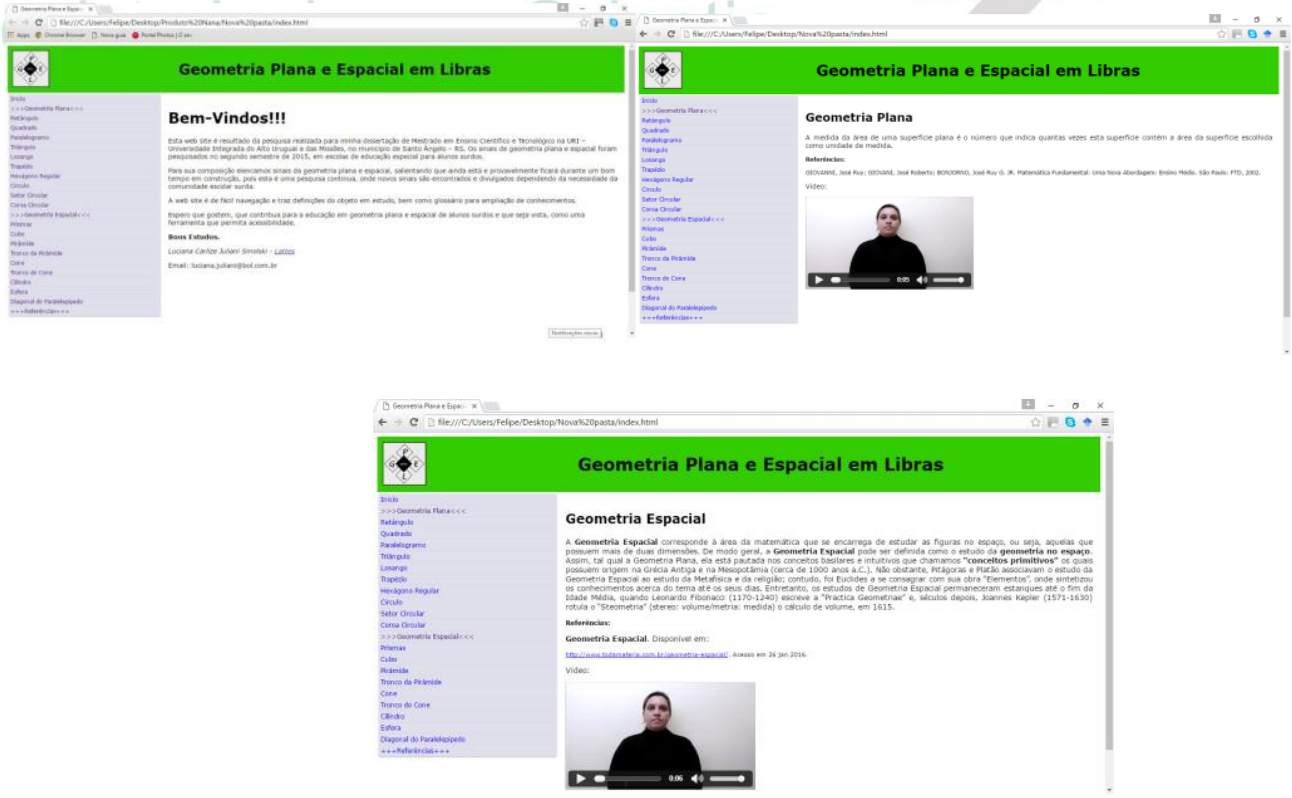

Fonte: autores da pesquisa 
Primeiramente, foi construído um quadro, onde foram classificados os sinais que já existiam na bibliografia atual e especializada, como, por exemplo, o dicionário de Capovilla e Raphael (2001), e, os sinais que eram frutos da pesquisa nas escolas. Posteriormente, os sinais, suas figuras representativas e fórmulas para a realização dos cálculos de geometria plana e espacial, foram inseridos por meio da programação em $H T M L$, na web site, e os sinais que são efetuados nos vídeos, fruto da pesquisa nas escolas especiais para surdos, foram executados pelos pesquisadores.

A web site está subdividida nos dois conteúdos abordados na pesquisa, geometria plana e espacial separadamente e conta, ainda, com links de glossário, onde o usuário pode se direcionar para a pesquisa de sinais relacionados com aquele que está sendo executado naquele momento na tela do computador.

É importante salientar que a web site continuará a ser implementada, uma vez que há muito o que pesquisar na área de ensino de matemática para surdos. Além disso, existem tópicos de geometria plana e espacial que necessitam ser pesquisados e acrescentados no site.

Por conseguinte, é latente a falta de sinais na área de exatas, como matemática, física e química, o que faz com que, os intérpretes e educadores, utilizem dos classificadores ou a datilologia (comunicação por meio de sinais feitos com os dedos). Os interpretes de Libras, quando não tem conhecimento de algum sinal que represente o objeto, ação, etc., bem como quando querem comunicar nomes próprios se utilizam da datilologia que "é um meio de verificação, questionamento ou veiculação da ortografia de uma palavra em português" (HONORA e FRIZANCO, 2010, p. 16),

Quanto a avaliação realizada pelos professores envolvidos na pesquisa, essa foi muito importante para a verificação da usabilidade do material por professores e alunos das escolas público alvo.

Essa verificação foi feita por meio do envio da web site para a escola e para o professor pesquisado, sendo, posteriormente, gravado em DVD (Disco Digital Versátil) 16 , juntamente com 4 (quatro) questões elaboradas pelo pesquisador e orientadores. Os questionamentos tiveram como objetivo verificar a facilidade de manuseio, efetiva usabilidade da web site nas aulas de geometria, bem como de se obter sugestões para melhoramentos da ferramenta e espaço aberto para comentários com relação à pesquisa. 
As quatro questões que foram enviadas para os professores pesquisados, juntamente com uma cópia da web site, tem o papel restrito de avaliação do material desenvolvido como resultado da pesquisa. Não tem ligação com as nove questões anteriormente citadas, a qual teve o intuito inicial de pesquisa e coleta de dados, não cunho avaliativo. Foi utilizando a resposta das 4 questões avaliativas que se assegurou a usabilidade da web site.

Reitera-se que o apelo visual na educação de surdos é de essencial importância, uma vez que, "aquelas atividades pedagógicas que combinam ilustrações, diagramas e informações escritas são de grande importância para a aprendizagem de alunos surdos" (SALES; PENTEADO; MOURA, 2015, p. 1273). Sendo assim, a criação de uma web site contempla as premissas de uma educação de surdos com um maior apelo visual.

Constatou-se que os professores que manusearam o DVD contendo a web site Geometria Plana e Espacial em Libras e consequentemente responderam ao questionário, que foi enviado via e-mail, gostaram do mesmo, de sua aparência e acharam de fácil manipulação.

A questão da possível utilização em sala de aula para educação de surdos, em geometria plana e espacial, também teve respaldo positivo, equivalendo a um auxiliar nas aulas de matemática onde estão sendo ministrados esses conteúdos. A web site foi bem avaliada como um instrumento de apoio, suprindo seu objetivo, salvo algumas melhorias, principalmente nos vídeos onde são executados os sinais, estes últimos avaliados pelos professores de alunos surdos. Numa posterior continuação da pesquisa a web site poderá ser avaliada por alunos surdos.

Averiguou-se, com as respostas obtidas por meio da avaliação feita pelos professores envolvidos na pesquisa, a grande, importância do cuidado na execução do sinal, sendo assim muito dos vídeos foram refeitos, buscando esmero e naturalidade no desempenho da língua brasileira de sinais.

Em uma das respostas obtidas, o professor sugeriu a execução em Libras das fórmulas matemáticas envolvidas no conteúdo de geometria plana e espacial, ressalta-se então que este não era o objetivo da pesquisa, mas sim os sinais das figuras geométricas planas e no espaço. Ficando assim uma ideia para uma futura implementação da web site. 
Uma das respostas dos professores foi a questão de muitas das figuras não ter sinal, e assim ter-se recorrido a datilologia. Por isso, urge a necessidade da ampliação da pesquisa para alcançar um maior número de escolas especiais para alunos surdos.

A relevância do trabalho se deu no fato da opinião de todos os envolvidos no trabalho de pesquisa se mostrar válida e principalmente a sua usabilidade para a educação de surdos, bem como o suporte para a aprendizagem de sinais na área de geometria plana e espacial.

\section{Considerações finais}

Percebe-se que a inclusão de surdos, é repleta de controvérsias, necessitando assim de mais discussões e pesquisas científicas, almejando seu melhoramento.

Ao se fazer uma análise da educação inclusiva de surdos percebe-se que o surdo durante muito tempo, viveu a margem da sociedade, apresentando muitas dificuldades para se comunicar e interagir, sendo tratado de forma como se não fosse possível educalo. Infelizmente esse ponto de vista se ampliou para dentro da escola, em detrimento a aprendizagem dos alunos surdos.

Há uma relevância ao trazer este assunto para uma discussão acadêmica, pois neste estudo foi possível verificar que no caso do conteúdo de geometria plana e especial, constatou-se que faltam sinais o que permeou a problemática da pesquisa, pois uma sinalização correta é de suma importância para a aprendizagem desses alunos.

A pesquisa junto as três Escolas de Educação para Alunos Surdos, localizadas em diferentes Regiões do Estado do Rio Grande do Sul, buscou identificar as terminologias matemáticas, que são utilizadas para trabalhar o conteúdo proposto.

$\mathrm{Na}$ análise qualitativa da pesquisa de campo, constata-se que a utilização do visual para a educação de surdos é um meio unanime, na opinião de todos os entrevistados. Quanto ao material didático utilizado na opinião de uma escola participante, ele é produzido para alunos ouvintes das escolas de educação básica regular, e sempre tem que ser adaptado aos alunos surdos, estes inseridos na escola regular inclusiva ou na escola especial para alunos surdos. Um grande aliado na educação de surdos é o uso das tecnologias, que proporcionam aos alunos e professores a utilização de pesquisas na internet e uso de softwares que tem grande apelo visual para uma aprendizagem colaborativa e efetiva.

Recebido em: $10 / 07 / 2020$

Aceito em: $1 \% 12 / 2020$ 
$\mathrm{Na}$ questão dos sinais matemáticos utilizados para a educação de geometria plana e espacial, constatou-se que ainda faltam muitos sinais de libras para o ensino de matemática, inclusive para toda área das exatas, como física e química, por exemplo. Assim o professor e tradutor interprete de Libras, lançam mão do uso dos classificadores.

Após análise da pesquisa bibliográfica e de campo realizada, foi possível construir a web site Geometria Plana e Espacial em Libras (GPEL), que se apresenta como um guia de terminologias matemáticas para educação de surdos em geometria plana e espacial e é subdividida, nos dois assuntos, Geometria Plana e Geometria Espacial. A construção de uma web site deu-se também pelo fato de oferecer grande apelo visual, o que constitui uma das premissas da educação de surdos.

Com as informações obtidas dos professores sobre o uso da webs site em sala de aula foram realizados ajustes de forma a contemplar as melhorias sugeridas para $\mathrm{o}$ mesmo. Deixa-se como sugestão a possibilidade de aprofundamento do tema.

\section{Referências}

ARNOLDO JUNIOR, Henrique; GELLER, Marlise. Emancipação de Sinais em Libras: um Estudo acerca dos Classificadores Matemáticos. Revista Brasileira de Tradução Visual. Vol.11, nº11, 2012.

BATISTA, Glayston Pereira; MOTTA, Carlos Eduardo Hermeto de Sá. Curso de Construção de Web Sites. Cadernos de Informática. Secretaria de Educação de Estado de Minas Gerais - MG, 2006, 119 p. Disponível em: $<$ http://portaldoprofessor.mec.gov.br/storage/materiais/0000014213.pdf〉. Acesso em: 14 jun. 2016.

BORGES, Fábio Alexandre; NOGUEIRA, Clélia Maria Ignatius. O ensino de matemática para surdos e as pesquisas educacionais atuais. In. Lippe, Eliza Marcia Oliveira e Alves, Fábio.de Souza. Educação para Surdos no Brasil: desafios e perspectivas para o novo milênio. Curitiba/PR: CRV, 2014.

BRASIL. Constituição Federal. $1988 . \quad$ Disponível em: < https://www.senado.leg.br/atividade/const/con1988/CON1988_05.10.1988/CON1988. asp>. Acesso em: 25 mai. 2015. 
BRASIL. LEI $\mathbf{N}^{\mathbf{1}}$ 10.436, DE 24 DE ABRIL DE 2002. Disponível em: http://www.planalto.gov.br/ccivil_03/LEIS/2002/L10436.htm. Acesso em: 12 jun. 2019.

CAI, Jinfa; MORRIS, Anne; HOHENSEE, Charles; HWANG, Stephen; ROBISON, Victoria; HIEBERT, James. Journal for Research in Mathematics Education. Vol. 50, no 1, 2, 2019. Disponível em: <https://www.nctm.org/Publications/Journalfor-Research-in-Mathematics-Education/2019/Vol50/Issue1/?ref=1>

CAPOVILLA, Fernando César; RAPHAEL, Walkiria Duarte. Dicionário Enciclopédico Ilustrado Trilíngue da Língua de Sinais Brasileira. Volume I e Volume II. [Ilustrações Silvana Marques]. - $2^{\mathrm{a}}$ ed. São Paulo: Editora da Universidade de São Paulo: Imprensa Oficial do Estado, 2001.

COSTA, Walber Cristiano Lima da; SILVEIRA, Marisa Rosâni Abreu da. Desafios da Comunicação no ensino de matemática para alunos surdos. BoEM-Boletim online de educação Matemática. Vol.2, n², p.72-87, 2014.

ENGLER, Karen S.; MACGREGOR, Cyntia J. Deaf Education Teacher Preparation: A Phenomenological Case Study of a Graduate Program With a Comprehensive Philosophy. Vol. 162, $\mathrm{n}^{\mathrm{o}}$ 5, p. 388-418, 2018. Disponível em: <https://pubmed.ncbi.nlm.nih.gov/29478996/>. Acesso em: 12 jun. 2020.

FRANZIN, Rozelaine de Fatima; GELLER, Marlise. Ações pedagógicas colaborativas e inclusivas na percepção do professor da educação básica e intérprete de libras no processo de formação continuada. Revista Interfaces da Educação. Vol.10, $\mathrm{n}^{\mathbf{0}} 30$, 2019.

GESSER, Audrei. LIBRAS? Que língua é essa?: crenças e preconceitos em torno da língua de sinais e da realidade surda. São Paulo: Parábola Editorial, 2009.

GOMES, Nilma Lino. Desigualdades e diversidade na educação. Educ. Soc. Campinas, 2012.

HARRISON, Nathan E. The University of New Mexico, Dissertação de Doutorado, 2018. Disponível em: <http://gateway.proquest.com/openurl?url_ver=Z39.882004\&rft_val_fmt=info:ofi/fmt:kev:mtx:dissertation\&res_dat=xri:pqm\&rft_dat=x ri:pqdiss:10840181>. 
MINAYO, Maria C. de S. (org). Pesquisa social: teoria método e criatividade. 32 ed.

Petrópolis, RJ: Vozes, 2012.

NEVES, Maria Janete Bastos das. A comunicação em matemática na sala de aula: obstáculos de natureza metodológica na educação de alunos surdos. Dissertação (Mestrado) Universidade Federal do Pará, Instituto de Educação Matemática e Científica, Programa de Pós-Graduação em Educação em Ciências e Matemática, Belém, 2011a.

NEVES, Maria Janete Bastos das. Comunicação em Matemática e Surdez: Os obstáculos do processo educativo. In: XIII CLAEM-IACME, Recife, Brasil, 2011b.

PEREIRA, Maria C. da C. et al. Libras Conhecimento Além dos Sinais. São Paulo: Pearson Prentice hall, 2011.

HONORA, Márcia. FRIZANCO, Mary L. E. Livro Ilustrado de Língua Brasileira de Sinais: desvendando a comunicação usada pelas pessoas com surdez. São Paulo: Ciranda Cultural, 2010.

PERLIN, Gladis; SOUZA, Regina Maria de. Política Inclusiva e Acesso ao Ensino Público: resistência e espaço de negociação. Revista Digital de Políticas Lingüísticas. Ano 7, Vol. 7. Setembro, 2015.

QUADROS, Ronice Muller de; Fleetwood, Earl (Org.); METZGER, Melanie (Org.). Signed Language Interpreting in Brazil. 1. ed. Washington, DC: Gallaudet University Press. Vol. 1. 114p, 2012.

REZENDE, Patrícia Luiza Ferreira. Implante coclear na constituição dos sujeitos surdos. 164 p. Tese (Doutorado em Educação). Universidade Federal de Santa Catarina. Florianópolis, 2010.

ROSA, Andréia da Silva. CRUZ, Cristiano Cordeiro. Internet: Fator de Inclusão da Pessoa Surda. Revista Online da Bibl. Prof. Joel Martins. Campinas. Vol. 2, nº 3. p. 38-64, jun. 2001.

SALES, Elielson Ribeiro. de; PENTEADO, Mirian Godoy. MOURA, Amanda Queiroz. A Negociação de Sinais em Libras como Possibilidade de Ensino e de Aprendizagem de Geometria. Bolema, Rio Claro - SP. Vol. 29, nº 53, p. 1268-1286, dez. 2015. 
SILVA, Angélica Bronzatto. de Paiva e; PEREIRA, Maria Cristina. da Cunha. O Aluno Surdo na Escola Regular: Imagem e Ação do Professor. Universidade de Campinas. Psicologia: Teoria e Pesquisa. Vol. 19 nº 2, p. 173-176. maio/ago. 2003.

SILVA, Marimar da; OLIVEIRA, Hagar de Lara Tiburcio de. Formação Profissional Integrada ao Ensino Médio: um estudo de caso com estudante surdo. Revista Educação Especial vol. 33, 2020. Disponível em: 〈https://periodicos.ufsm.br/educacaoespecial〉. Acesso em: 12 mai. 2020.

SKLIAR, Carlos. A surdez: um olhar sobre as diferenças. Porto Alegre: Mediação, 1998.

SKLIAR, Carlos. Os Estudos Surdos em Educação: problematizando a normalidade. In: SKLIAR, Carlos. (Org.). A surdez: um olhar sobre as diferenças. 6. ed. Porto Alegre: Editora Mediação, 2013.

SLOMSKI, Vilma Geni. Educação bilíngue para surdos: concepções e implicações práticas. $1^{\circ}$ ed. / Curitiba: Juruá, 2012.

SCHNEIDER, Roseléia. Educação de surdos: inclusão no ensino regular. Passo Fundo; Ed. Universidade de Passo Fundo, 2006.

ZUFFI, Edna M. JACOMELLI, Cristiane V. PALOMBO, Renato D. Pesquisa sobre a inclusão de alunos com necessidades especiais no Brasil e a aprendizagem em Matemática. XIII CIAEM-IACME, Recife, Brasil, 2011. 